\title{
Histamine targets myeloid-derived suppressor cells and improves the anti-tumor efficacy of PD-1/PD-L1 checkpoint blockade
}

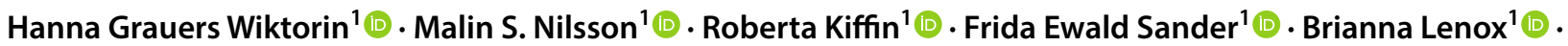

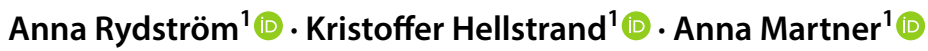

Received: 11 May 2018 / Accepted: 26 September 2018 / Published online: 12 October 2018

(c) The Author(s) 2018

\begin{abstract}
Myeloid-derived suppressor cells (MDSCs) are immature monocytes and granulocytes that impede immune-mediated clearance of malignant cells by multiple mechanisms, including the formation of immunosuppressive reactive oxygen species (ROS) via the myeloid cell NADPH oxidase (NOX2). Histamine dihydrochloride (HDC), a NOX2 inhibitor, exerts anti-cancer efficacy in experimental tumor models but the detailed mechanisms are insufficiently understood. To determine effects of HDC on the MDSC compartment we utilized three murine cancer models known to entail accumulation of MDSC, i.e. EL-4 lymphoma, MC-38 colorectal carcinoma, and 4T1 mammary carcinoma. In vivo treatment with HDC delayed EL-4 and 4T1 tumor growth and reduced the ROS formation by intratumoral MDSCs. HDC treatment of EL-4 bearing mice also reduced the accumulation of intratumoral MDSCs and reduced MDSC-induced suppression of T cells ex vivo. Experiments using GR1-depleted and Nox2 knock out mice supported that the anti-tumor efficacy of HDC required presence of NOX2 ${ }^{+}$GR $1^{+}$ cells in vivo. In addition, treatment with HDC enhanced the anti-tumor efficacy of programmed cell death receptor 1 (PD-1) and PD-1 ligand checkpoint blockade in EL-4- and MC-38-bearing mice. Immunomodulatory effects of a HDC-containing regimen on MDSCs were further analyzed in a phase IV trial (Re:Mission Trial, ClinicalTrials.gov; NCT01347996) where patients with acute myeloid leukemia received HDC in conjunction with low-dose IL-2 (HDC/IL-2) for relapse prevention. Peripheral CD14 ${ }^{+} \mathrm{HLA}_{-} \mathrm{DR}^{-/ \text {low }}$ MDSCs (M-MDSCs) were reduced during cycles of HDC/IL-2 therapy and a pronounced reduction of M-MDSCs during HDC/IL-2 treatment heralded favorable clinical outcome. We propose that anti-tumor properties of HDC may comprise the targeting of MDSCs.
\end{abstract}

Keywords Myeloid-derived suppressor cells $\cdot$ Histamine dihydrochloride $\cdot$ NOX2 $\cdot$ Reactive oxygen species $\cdot$ PD-1 Checkpoint inhibition

\section{Abbreviations}

AML Acute myeloid leukemia

ATRA All-trans retinoic acid

CR Complete remission

This study was in part presented at the Regulatory Myeloid

Suppressor Cells Conference (RMSC), June 16-18 2016,

Philadelphia, USA.

Electronic supplementary material The online version of this article (https://doi.org/10.1007/s00262-018-2253-6) contains supplementary material, which is available to authorized users.

Anna Martner

anna.martner@gu.se

1 TIMM Laboratory, Sahlgrenska Cancer Center, University of Gothenburg, Medicinaregatan 1F, Box 425, 41390 Göteborg, Sweden

\begin{tabular}{|c|c|}
\hline C1D1 & Cycle 1 , day 1 \\
\hline C1D21 & Cycle 1 , day 21 \\
\hline $\mathrm{C} 3 \mathrm{C} 1$ & Cycle 3, day 1 \\
\hline C3D21 & Cycle 3 , day 21 \\
\hline D-peptide & Typ-Lys-Tyr-Met-Val-d-Met \\
\hline fMLF & $N$-formyl-Met-Leu-Phe \\
\hline G-MDSC & $\begin{array}{l}\text { Granulocytic myeloid-derived suppressor } \\
\text { cells }\end{array}$ \\
\hline $\mathrm{HDC}$ & Histamine dihydrochloride \\
\hline $\mathrm{H}_{2} \mathrm{R}$ & Histamine $\mathrm{H}_{2}$-type receptor \\
\hline IMC & Immature myeloid cells \\
\hline LFS & Leukemia-free survival \\
\hline MDSC & Myeloid-derived suppressor cells \\
\hline M-MDSC & Monocytic myeloid-derived suppressor cells \\
\hline NOX2 & NADPH oxidase type 2 \\
\hline $\mathrm{O}_{2}^{-}$ & Superoxide anion \\
\hline
\end{tabular}


$\mathrm{OH} \quad$ Hydroxyl radical

ROS Reactive oxygen species

\section{Introduction}

Immature myeloid cells (IMCs) accumulate in peripheral organs and in the tumor microenvironment in human and experimental cancer. IMCs normally differentiate into mature myeloid cells such as macrophages, dendritic cells (DCs), and granulocytes upon migration from the bone marrow (BM) to the periphery. This differentiation is frequently defective in cancer with ensuing expansion of IMCs, presumably as the result of the formation of differentiationinhibitory factors by malignant cells. IMCs may be further activated to acquire immunosuppressive properties by factors produced by activated $\mathrm{T}$ cells and tumor stroma cells. These immature immunosuppressive cells are denoted myeloid-derived suppressor cells (MDSCs) [1].

Reactive oxygen species (ROS) are short-lived compounds that arise from electron transfer across biological membranes to form superoxide anion $\left(\mathrm{O}_{2}^{-}\right)$from molecular oxygen. ROS comprise oxygen radicals such as $\mathrm{O}_{2}{ }^{-}$and hydroxyl radicals ( $(\mathrm{OH})$ along with non-radicals, including hydrogen peroxide. ROS, formed by the myeloid cell NADPH oxidase (NOX2), are pivotal mediators in the defense against microorganisms [2]. When released into the extracellular space ROS may also trigger dysfunction and apoptosis in neighboring cells, including lymphocytes [3]. This pathway of immunosuppression is exploited by MDSCs, which show increased ROS production by virtue of up-regulated NOX2 activity. In the absence of functional NOX2, MDSCs are less prone to suppress T cells and instead differentiate into macrophages and DCs [4].

Human and murine MDSCs occur in granulocytic (G-MDSCs) and monocytic (M-MDSCs) forms [5]. Phenotypically, human G-MDSCs share the surface markers of neutrophils but differ in buoyant density. Human M-MDSCs are phenotypically distinguished from normal monocytes by their expression density of HLA-DR, where monocytes are CD $14^{+}$HLA-DR ${ }^{\text {high }}$ whereas M-MDSCs are $\mathrm{CD} 14^{+} \mathrm{HLA}-\mathrm{DR}{ }^{-/ \text {low }}[6]$. Human M-MDSCs as well as G-MDSCs reportedly produce NOX2-derived ROS and suppress $\mathrm{T}$ cell functions in a ROS-dependent manner [7]. Murine MDSCs express GR1 and CD11b, and the murine G-MDSC and M-MDSC subsets are distinguished by their expression of the GR1 epitopes Ly6G and Ly6C. Hence, G-MDSCs are CD11 ${ }^{+} \mathrm{Ly}_{6 \mathrm{G}}^{+} \mathrm{Ly} 6 \mathrm{C}^{\text {low }}$, whereas M-MDSCs are $\mathrm{CD} 11 \mathrm{~b}^{+} \mathrm{Ly}_{6 \mathrm{G}}{ }^{-} \mathrm{Ly} 6 \mathrm{C}^{\text {high }}$ [8]. In mice, the capacity to suppress $\mathrm{T}$ cells via ROS production is largely confined to the G-MDSC subset [9], whereas murine M-MDSCs rely on nitric oxide synthase (iNOS) for their immunosuppressive properties [1].
The presence of MDSCs is assumed to facilitate the growth and spread of tumors and may also dampen the efficacy of cancer immunotherapies [10]. Several approaches to target MDSCs have been proposed, including blocking the recruitment of MDSCs to the tumor microenvironment [11], eliminating MDSCs [12], targeting their immunosuppressive features [13] or facilitating their maturation [14]. Histamine is a pleiotropic biogenic amine stored in mast cells and basophilic leukocytes [15]. We recently reported that the administration of histamine dihydrochloride (HDC), a histamine salt that dissociates into histamine in solution, promotes the development of monocyte-derived DCs in vitro and in vivo and that these pro-differentiating properties were mediated by inhibition of NOX2 [16]. In addition, Yang et al. showed that mice that lack the histamine-forming histidine decarboxylase, with ensuing histamine deficiency in tissues, are highly susceptible to chemically induced cancer. These histamine-deficient mice were reported to accumulate MDSCs to a higher extent than their wild-type counterparts during the progression of solid tumors [17].

Beyond its purported role in myelopoiesis, HDC inhibits ROS production by myeloid cells in a NOX2-dependent manner and thus reduces the immunosuppressive features of various NOX2 $2^{+}$myeloid cells [3]. HDC is approved in Europe, in conjunction with low-dose IL-2, for relapse prevention in patients with acute myeloid leukemia (AML) who have achieved complete remission (CR) after chemotherapy [18]. While details regarding the anti-leukemic action of the HDC component remain to be determined, it has been proposed that HDC targets NOX2-derived immunosuppressive ROS to protect anti-tumor lymphocytes from ROS-induced inactivation [18].

The present study aimed at determining effects of HDC on MDSCs in three murine tumor models known to entail pronounced MDSC accumulation. We report that the systemic administration of HDC, by targeting NOX2, rendered intratumoral MDSCs less immunosuppressive and delayed the growth of murine EL-4 lymphoma and 4T1 breast cancer and, also, that these properties of HDC translated into improved anti-tumor efficacy of antibodies against the programmed cell death receptor 1 (PD-1) and the PD-1 ligand (PD-L1) in EL-4and $\mathrm{MC}$-38-bearing mice. In addition, the administration of HDC/IL-2 to AML patients in CR was associated with reduced counts of M-MDSCs in blood, which predicted reduced risk of leukemic relapse. We hypothesize that anti-tumor effects of HDC may involve the targeting of MDSCs. 


\section{Materials and methods}

\section{Culture of EL-4, 4T1 and MC-38 cells}

The EL-4 and 4T1 cell lines were maintained in RPMI 1640 (VWR, Stockholm, Sweden) and the MC-38 cell line in DMEM without sodium pyruvate (Sigma-Aldrich, St. Louis, MO, USA). Medium was supplemented with $10 \%$ fetal calf serum (FCS), $100 \mu \mathrm{g} / \mathrm{ml}$ penicillin, $100 \mu \mathrm{g} / \mathrm{ml}$ streptomycin and $2 \mathrm{mM}$ L-glutamine (EL-4 and $4 \mathrm{~T} 1$ cells) at $37^{\circ} \mathrm{C}$ and $5 \% \mathrm{CO}_{2}$. Adherent $4 \mathrm{~T} 1$ and MC-38 cells were detached by trypsinization before expansion. Cells were cultured in vitro for 1-2 weeks prior to inoculation into mice.

\section{Tumor cell proliferation assay}

EL-4 and MC-38 cells were stained with CellTraceViolet Proliferation Kit (Invitrogen, Carlsbad, CA, USA) according to the manufacturer's instructions. The cells were cultured in the presence or absence of $100 \mu \mathrm{M}$ HDC (Sigma-Aldrich) for 1-4 days following assessment of proliferation using a four-laser BD LSRFortessa $(405,488,532$, and $640 \mathrm{~nm}$ from BD Biosciences, San Diego, CA, USA) and analyzed using FACSDiva software (version 6 or later; BD Biosciences).

The 4T1 cells were cultured for 5 days in the presence or absence of $100 \mu \mathrm{M}$ HDC. At $30 \mathrm{~min}$ or $8 \mathrm{~h}$ prior to collection of cells, BrDU at a final concentration of $10 \mu \mathrm{M}$ was added to the medium. The cells were then fixed, permeabilized, incubated with DNase A, and analyzed on a BD LSRFortessa for BrdU incorporation using the BD Pharmingen BrdU Flow Kit (BD Biosciences).

\section{EL-4, 4T1 and MC-38 models}

Six- to eight-week-old female C57BL/6J and BALB/c mice were obtained from Charles River (Charles River Laboratories, Sulzfeld, Germany). B6.129S6-Cybb ${ }^{\text {tm1Din }}$ [Nox2knock out (KO)] mice were originally obtained from Jackson Laboratory (Bar Harbor, ME, USA) and bred in-house. C57BL/6J mice and Nox2-KO mice were injected subcutaneously (s.c.) with $1.75-3 \times 10^{5}$ EL-4 cells or $5-10 \times 10^{5}$ MC-38 cells. BALB/c mice were injected s.c. with $4 \times 10^{5}$ 4T1 cells. Mice were treated by intraperitoneal (i.p.) injections of HDC at $1500 \mu \mathrm{g} / \mathrm{mouse}$ (EL-4- and MC-38-bearing mice) or $1000 \mu \mathrm{g} /$ mouse (4T1-bearing mice) three times per week starting 1 day before tumor inoculation, or with i.p. injections of a mixture of antibodies against PD-1 ( $\alpha$-PD1 ; 100-240 $\mu \mathrm{g} / \mathrm{mouse}$; RMP1-14; Nordic Biosite, Stockholm, Sweden) and PD-L1 ( $\alpha-P D-L 1 ; 100-240 \mu \mathrm{g} /$ mouse; 10F.9G2; Nordic Biosite) 3, 6 and 10 days after tumor inoculation, or with the addition of HDC to the regimen of
PD-1/ $\alpha$-PD-L1 antibodies. Effects of HDC on EL-4 tumor growth confirm and extend a previous study [16]. In some experiments, EL-4 cells were treated with $100 \mu \mathrm{M}$ HDC in vitro for 3-5 days prior to tumor inoculation. Mice inoculated with in vitro HDC-treated cells did not receive further in vivo treatment. $\mathrm{GR} 1^{+}$cells depletion in EL-4-bearing mice was achieved by i.p. injections of GR1-neutralizing antibodies (250 $\mu \mathrm{g}$, RB6-8C5, BioXcell, West Lebanon, USA) every other day starting once tumors became palpable.

The size of tumors was measured three times per week as the length $\times$ width. When several experiments were analyzed, the tumor size was normalized against the mean tumor size of untreated WT control mice, untreated GR1 depleted WT mice, or untreated Nox2-KO control mice at the termination of each experiment. Mice were sacrificed and tumors and spleens harvested 2-3 weeks after tumor cell inoculation when the size of the largest tumors had reached a diameter of $1-1.5 \mathrm{~cm}$.

\section{Processing of spleens, tumors and BM}

Single cell suspensions of tumors were prepared by enzymatic digestion using a Tumor Dissociation Kit (Miltenyi Biotec, Lund, Sweden) along with mechanical dissociation utilizing a gentleMACS Dissociator (Miltenyi Biotec) according to the manufacturer's instructions. BM cells were isolated from femur and tibia of tumor-free naïve mice by crushing the bones using a mortar. BM cells were rinsed and spleens were mashed through a $70-\mu \mathrm{m}$ strainer and depleted of erythrocytes by Red Blood Cell Lysis buffer (Sigma-Aldrich).

\section{Flow cytometry analysis of murine samples}

Single cell suspensions from tumors and spleens were incubated for 5 min with $F_{c}$-block (BD Biosciences) and then stained with either a myeloid panel of antibodies comprising CD45-BV786 (Clone 30-F11, BD Biosciences), GR1-PE (Clone RB6-8C5, BD Biosciences), CD11b-BV711 (Clone MI/70, BD Biosciences), Ly6C-PerCpCy5.5 (Clone AL-21, BD Biosciences), Ly6G-FITC (Clone IA8, BD Biosciences) and DAPI (Invitrogen) or a lymphoid panel of antibodies comprising CD45-AlexaFlur700 (Clone 30-F11, BD Biosciences), CD3-PE (Clone 145-2C11, eBioscience), NKp46PE-Cy7 (Clone 29A1.4, eBioscience), CD4-APC (Miltenyi Biotec), CD8-FITC (Miltenyi Biotec), CD44-BV711 (Clone IM7, BD Biosciences), CD62L-BV786 (Clone MEL-14, BD Biosciences), PD-1-BV605 (Clone J43, BD Biosciences) and DAPI (Invitrogen). In some experiments MDCSs were also analyzed for iNOS-PE (Clone CXNFT, eBioscience) expression. Cells were acquired on a BD LSRFortessa and analyzed using FACSDiva. 


\section{T cell suppression assay}

$\mathrm{GR}^{+}{ }^{+}$cells were isolated from spleens of EL-4-bearing mice and from BM of tumor-free naïve mice. Single cell suspensions were stained with a Ly6G/C-biotin antibody (clone RB6-8C5, BD Biosciences) followed by incubation with streptavidin-conjugated magnetic beads and positively selected by use of a MACS magnet (Miltenyi Biotech) according to the manufacturer's instructions. The purity was consistently $>80 \%$. The purified GR $1^{+}$cells expressed CD11b $\{98 \% \pm 0.48$, [mean \pm standard error of the mean $(\mathrm{SEM})], n=6\}$. Splenocytes from OT-1 mice (Rag2/OT-1, Taconic, USA) were stained with CellTraceViolet Proliferation Kit (Invitrogen) according to the manufacturer's instructions. CellTraceViolet ${ }^{+}$OT-1 splenocytes were cultured at a 1:1 ratio with $\mathrm{GR} 1^{+}$cells from EL-4-bearing or naïve mice in the presence of $10 \mu \mathrm{g} / \mathrm{ml}$ the OT-1 T cell specific peptide SIINFEKL (Sigma-Aldrich) or the control peptide gp100 IMDQVPFSV (AnaSpec, Fremont, USA). The cells were cultured for 3 days in RPM1 1640 supplemented with $10 \%$ FCS, $100 \mu \mathrm{g} / \mathrm{ml}$ penicillin, $100 \mu \mathrm{g} / \mathrm{ml}$ streptomycin and $2 \mathrm{mM}$ L-glutamine at $37{ }^{\circ} \mathrm{C}$ and $5 \% \mathrm{CO}_{2}$ and thereafter stained with FITC-anti-CD8 (Miltenyi Biotec) before measuring $\mathrm{T}$ cell proliferation by flow cytometry. Results were analyzed with FlowJo Version 10.1 (TreeStar, Ashland, USA).

\section{Generation of human monocyte-derived MDSCs}

PBMCs were prepared from healthy blood donor buffy coats by Ficoll-Paque (Lymphoprep, Nycomed, Oslo, Norway) density centrifugation. Monocytes were isolated by adherence and cultured in Iscoves' medium supplemented with $10 \%$ human $\mathrm{AB}$ serum, $2 \mathrm{mM}$ L-glutamine, $100 \mu \mathrm{g} / \mathrm{ml}$ penicillin, $100 \mu \mathrm{g} / \mathrm{ml}$ streptomycin, $1 \mathrm{ng} / \mathrm{ml}$ interleukin 6 (hIL6 , Sigma-Aldrich) and $10 \mathrm{ng} / \mathrm{ml}$ granulocyte macrophage colony-stimulating factor (hGM-CSF, Peprotech, Rocky Hill, USA) in the presence or absence of $100 \mu \mathrm{M}$ HDC. In control experiments, adherent monocytes were cultured in the absence of cytokines. One-half of the medium was replaced and HDC was again added after 2 days of culture. Cells were examined for expression of HLA-DR (antibody: HLA-DR-APC-Cy7, Clone C243, BD Biosciences) by flow cytometry after 5 days of culture.

\section{Detection of ROS by chemiluminescence}

Superoxide anion production in response to the hexapeptide Typ-Lys-Tyr-Met-Val-d-Met (D-peptide, R\&D Systems, Minneapolis, MN, USA) or $N$-formyl-Met-Leu-Phe (fMLF, Sigma-Aldrich) by murine cells from tumors and spleens or by human cytokine-induced MDSCs was measured by isoluminol chemiluminescence (CL) as described [19]. Results are presented as curves displaying continuous ROS formation or as the area under the curve normalized to the mean area under the curve for cells from tumor-bearing control mice.

\section{MDSCs in a clinical trial of HDC/IL-2}

In a phase IV trial (Re:Mission; ClinicalTrials.gov; NCT01347996), 84 adult patients with AML in first complete remission received ten consecutive 21-day cycles of HDC and interleukin-2 (HDC/IL-2) for 18 months or until relapse or death. The trial is described in detail elsewhere $[20,21]$. Blood was collected before and after the first and third HDC/IL-2 treatment cycle. PBMCs were isolated and cryopreserved at local sites and shipped on dry ice to the central laboratory at the Sahlgrenska Cancer Center, University of Gothenburg, Sweden.

PBMCs were stained, as described in [20], with a panel of antibodies against myeloid cells to determine the content of MDSCs in blood. The MDSC-panel included the following antibodies from BD Biosciences: CD3-PerCpCy5.5 (clone HIT3A), CD19-PerCPCy5.5 (SJ25C1), CD16-Brilliant Violet 605 (3G8), HLA-DR-APCH7 (G46-6), CD14-PECy7 $(\mathrm{M} \varphi \mathrm{P} 9)$ and $\mathrm{CD} 56-\mathrm{PerCp}$ eflour 710 from CMSSB, Thermo Fischer Scientific, USA. Stained samples were acquired on a BD FACSAria. PBMCs were also stained using a second panel to determine the expression level of $\mathrm{H}_{2} \mathrm{R}$ and gp91 ${ }^{\text {phox }}$ (the catalytic subunit of NOX2) on MDSCs using the following stains and antibodies: LIVE/DEAD fixable yellow stain (Life Technologies, Grand Island, NY, USA), CD33PECy7 (P67.6), CD16-APC-H7 (3G8), HLA-DR-Qdot605 (G46-6) (all from BD Biosciences), CD14-Qdot655 (TüK4, Life Technologies), anti-histamine $\mathrm{H}_{2}$ receptor (polyclonal rabbit IgG, MBL International, Woburn, MA, USA), goat anti-rabbit-PerCpCy5.5 and gp91 ${ }^{\text {phox }}$-FITC (7D5, MBL International). Samples were analyzed on a four-laser BD LSRFortessa flow cytometer and data analysis was performed using FlowJo software, version 7.6.5 or later (TreeStar, AShlandm OR). Sixty-two patients were analyzed using the MDSC-panel and 49 patients were analyzed using the $\mathrm{H}_{2} \mathrm{R}$ and gp91 ${ }^{\text {phox }}$ panel. The selection of patients for analysis was based on the availability of viably frozen PBMCs. Differential counts, obtained from participating centers, were used to calculate the absolute counts of MDSCs in patient blood.

\section{Statistics}

Statistical analyses were performed using GraphPad Prism software (version 6.0 or later). Paired and unpaired $t$ tests were utilized for comparisons between two groups and one and two-way ANOVA followed by Holm-Sidak's test was used for comparisons between $>$ two groups. In experiments 
using MC-38 tumor-bearing mice, tumors were completely eradicated by immunotherapy in some animals. In these experiments, the linear mixed effects model was employed to compare the slope of tumor growth curves from day 6 until the experimental endpoint, or until the first size $=0$ measurement. For survival analysis, the logrank (Mantel-Cox) test was utilized to compare patients showing a strong or a low/no reduction of MDSCs (dichotomized by the median reduction) during treatment with HDC/IL-2.

\section{Results}

\section{HDC reduces tumor progression by targeting NOX2 ${ }^{+}$ MDSCs}

In agreement with a previous report [16], the systemic administration of HDC significantly reduced the in vivo growth of EL-4 lymphomas (Fig. 1a). HDC also reduced the growth of 4T1 mammary carcinoma (Fig. 1b) with a similar, albeit non-significant, trend observed in MC38-bearing mice (Supplementary Fig. 1a). To elucidate the role of MDSCs for the anti-tumor efficacy of HDC, mice inoculated with EL-4 lymphoma cells were depleted of GR $1^{+}$cells using the GR1-neutralizing antibody RB6-8C5. As determined by FACS analysis at the end of the experiment, intratumoral GR $1^{+} \mathrm{CD} 11 \mathrm{~b}^{+}$MDSCs were reduced by approximately $75 \%$ following GR1 antibody treatment (Supplementary Fig. 2a). In GR1-depleted animals, treatment with HDC did not affect EL-4 lymphoma growth (Fig. 1c) but significantly reduced lymphoma growth in simultaneously performed experiments in non-GR1-depleted animals ( $p=0.03$ at day 10, Students' $t$ test, Supplementary Fig. 2b). In agreement with a previous report [22] treatment with GR1-neutralizing antibodies per se did not significantly impact on EL-4 lymphoma growth (Supplementary Fig. 2b).

The effect of HDC treatment on EL-4 lymphoma growth was also evaluated in Nox2-KO mice, where MDSCs accumulate but do not generate NOX2-derived ROS. HDC did not alter lymphoma growth in the Nox2-KO mice (Fig. 1d). HDC did not affect the proliferation or cell cycling of EL-4 or 4T1 cells but slightly reduced the proliferation of MC-38 cells after two days in culture (Supplementary Fig. 1b-f). In vivo growth of EL-4 cells was not affected by previous in vitro exposure to HDC (Supplementary Fig. 1g).

\section{Effects of HDC on myeloid and lymphoid populations in tumor-bearing mice}

In accordance with a previous report [9], EL-4 and 4T1 growth was associated with a pronounced increase of MDSCs in tumors and spleens (Fig. 2a and Supplementary Fig. 3a). Treatment of mice with HDC significantly
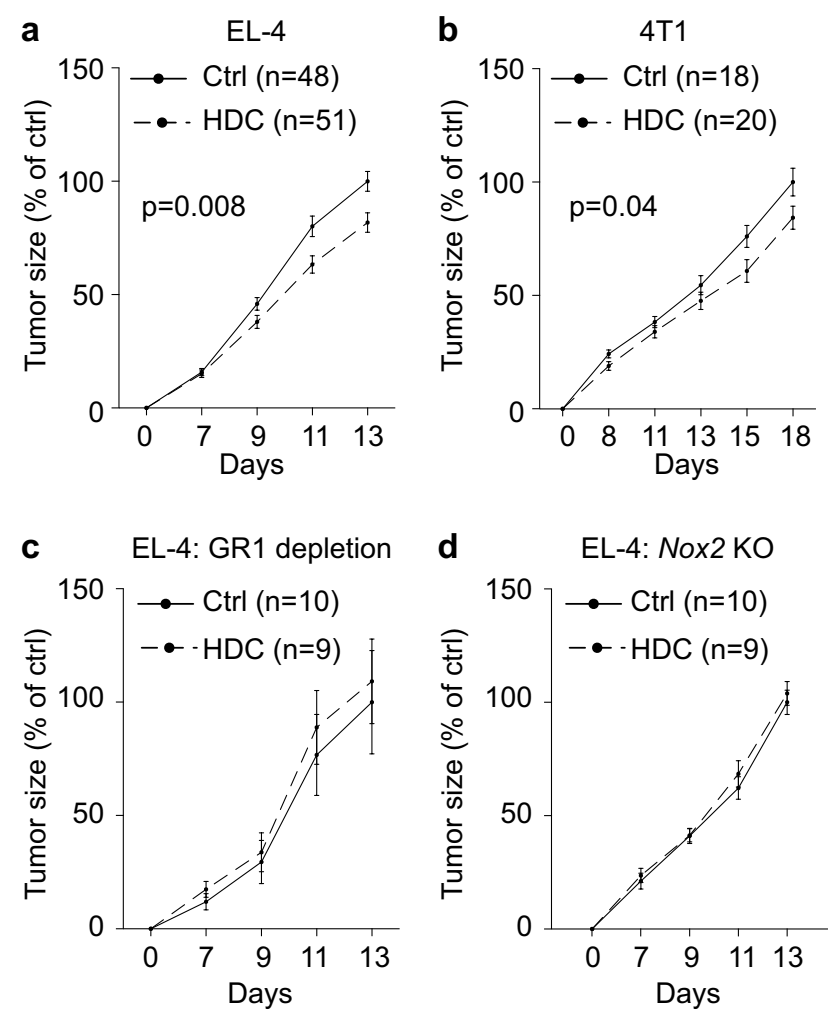

Fig. 1 HDC reduces the growth of EL-4 lymphoma and 4T1 mammary carcinoma in mice. Mice were either untreated (Ctrl, solid lines) or treated with HDC (dashed lines) thrice weekly starting 1 day before tumor cell inoculation. a, b Growth of a EL-4 lymphomas and b 4T1 tumors in wild-type mice. c EL-4 growth in wild-type mice depleted of $\mathrm{GR}^{+}{ }^{+}$cells. d EL-4 tumor growth in Nox2-KO mice. The tumor size was normalized against the mean tumor size of control mice at the end of each experiment, i.e. against untreated WT mice in a, b, untreated GR1-depleted WT mice in c, and untreated Nox2-KO mice in $\mathbf{d}$. Results were analyzed using two-way ANOVA

reduced the accumulation of MDSCs within EL-4 lymphomas, but not in spleen (Fig. 2a). Mice inoculated with 4T1 cells acquired enlarged spleens where approximately $50 \%[52 \% \pm 2.5($ mean \pm SEM $), n=30]$ of splenocytes were MDSCs. Treatment of mice with HDC reduced the number of splenocytes but did not alter the content of MDSCs in tumors or spleens in this model (Fig. 2b and Supplementary Fig. 3a). The vast majority of MDSCs in tumor-bearing mice were G-MDSCs. HDC did not affect the distribution of MDSC subtypes in EL-4-bearing mice (Supplementary Fig. 3b) but significantly reduced the accumulation of splenic and tumor-infiltrating M-MDSCs in 4T1-bearing mice (Supplementary Fig. 3c).

We did not observe a significant increase in the number of tumor-infiltrating or splenic $\mathrm{CD} 8^{+} \mathrm{T}$ cells in HDC-treated EL-4 or 4T1-bearing mice (Supplementary Fig. 4a, b). However, a negative correlation was noted between the percentage of intratumoral MDSCs and 

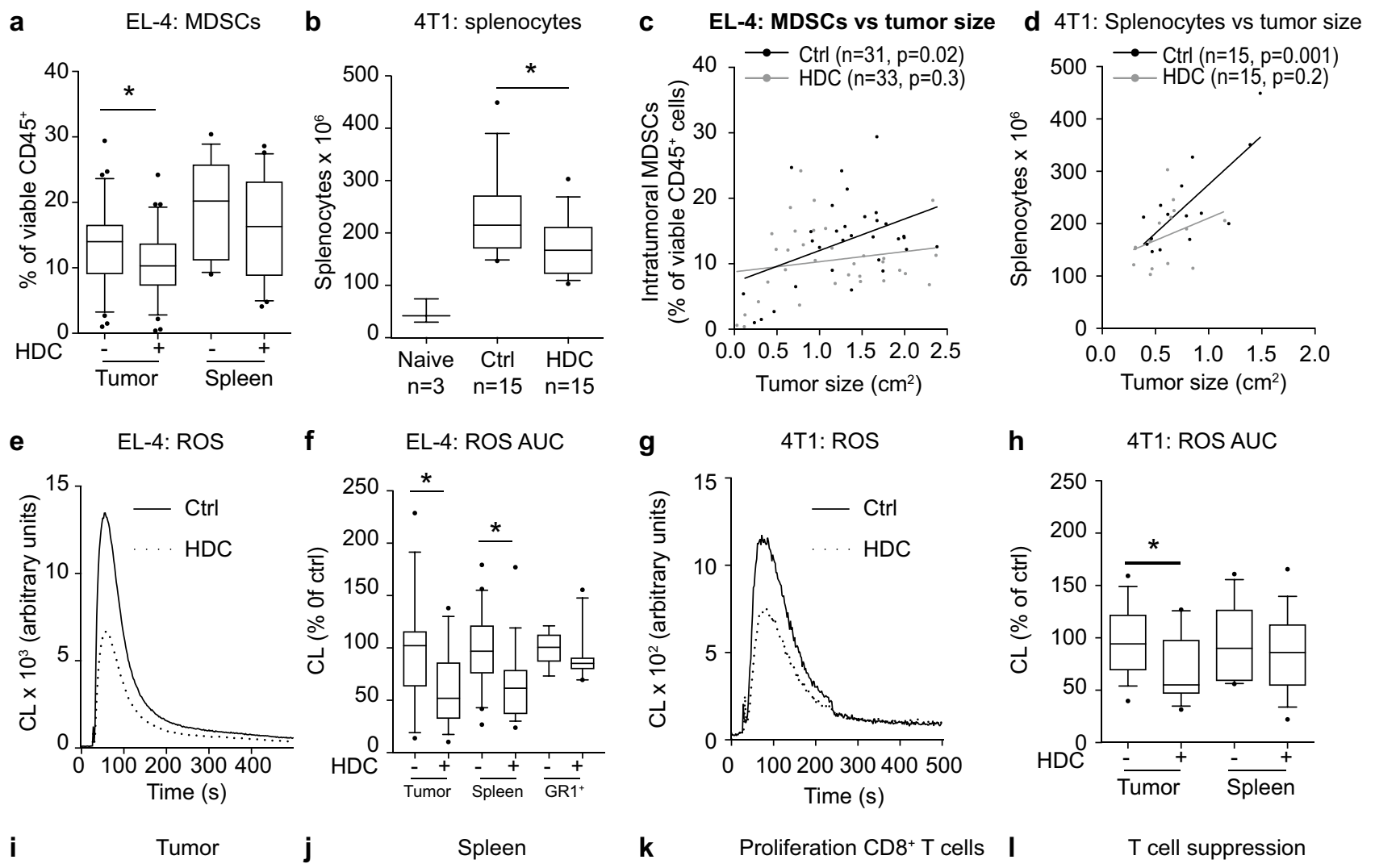

k

Proliferation $\mathrm{CD}^{+} \mathrm{T}$ cells
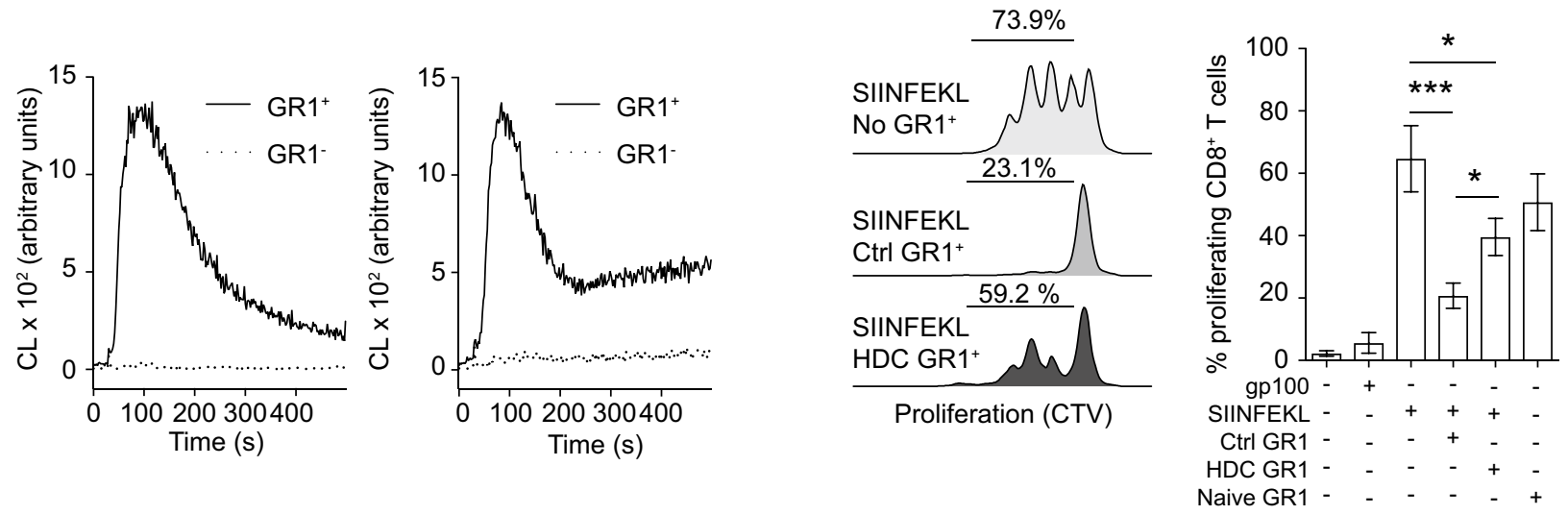

tumor-infiltrating $\mathrm{CD} 8^{+} \mathrm{T}$ cells in both models (Supplementary Fig. 4c, d). Treatment of mice with HDC significantly enhanced the proportion of $\mathrm{CD}_{2} \mathrm{~L}^{-}$cells (comprising $\mathrm{CD} 44^{+}$effector memory and $\mathrm{CD} 44^{-}$effector populations) among $\mathrm{CD} 8^{+} \mathrm{T}$ cells in EL-4-bearing mice with a similar trend in the 4T1 model (Supplementary Fig. 4e, f). Treatment of EL-4-bearing mice with HDC did not significantly alter the percentage of intratumoral $\mathrm{CD} 4^{+} \mathrm{T}$ cells, NK cells or B cells but slightly reduced the percentage of $\mathrm{CD} 4^{+} \mathrm{T}$ cells and $\mathrm{NK}$ cells in spleens (Supplementary Fig. 4g-i).

\section{HDC reduces NOX2-dependent immunosuppression in MDSCs}

To determine whether the reduction in MDSCs and splenocytes following HDC treatment was secondary to the reduced tumor size we correlated the tumor size with MDSC content in the EL-4 model and with the number of splenocytes in the 4T1 model. A positive correlation was noted between the size of tumors and the percentage of intratumoral MDSCs in EL-4-bearing control mice and with splenocytes in 4T1-bearing control mice (Fig. 2c, d). No such correlations were observed in HDC-treated EL-4or 4T1-bearing mice (Fig. 2c, d), suggesting that MDSCs 
४Fig. 2 HDC reduces the immunosuppressive properties of MDSCs in mice carrying EL-4 and 4T1 tumors. EL-4-bearing mice were euthanized after 2 weeks and 4T1-bearing mice after 3 weeks of tumor growth when the mean tumor size of untreated mice reached approximately $1.5 \mathrm{~cm}^{2}$. a Accumulation of intratumoral and splenic MDSCs in EL-4-bearing mice. Content of MDSCs was examined in control mice ( $n=31$ for intratumoral MDSCs, $n=19$ for splenic MDSCs) and in HDC-treated mice ( $n=33$ for intratumoral MDSCs, $n=21$ for splenic MDSCs). b Counts of splenocytes in tumor-free (naïve) and control or HDC-treated 4T1-bearing mice. Correlation between $\mathbf{c}$ intratumoral MDSCs and tumor size in EL-4-bearing mice or d splenocytes and tumor size in 4T1-bearing mice in control (black) and HDC-treated (grey) animals. e Mean D-peptide-induced ROS production from leukocytes recovered from tumors of control (solid line, $n=18$ ) and HDC-treated (HDC, dotted line, $n=17$ ) EL-4-bearing mice. $\mathbf{f}$ ROS formation (area under the curve) in response to D-peptide by single cell suspensions from tumors, spleens or splenocyte-derived $\mathrm{GR} 1^{+}$cells isolated from control (tumor $n=18$, spleen $n=20, \mathrm{GR} 1^{+}$ $n=9$ ) or HDC-treated (tumor $n=17$, spleen $n=19, \mathrm{GR}^{+} n=11$ ) EL-4-bearing mice. $\mathbf{g}$ Mean D-peptide-induced ROS production from leukocytes recovered from tumors of control (solid line, $n=15$ ) and HDC-treated (HDC, dotted line, $n=14$ ) 4T1-bearing mice. h ROS formation (area under the curve) in response to D-peptide stimulation by single cell suspensions from tumors or spleens isolated from control (tumor $n=15$, spleen $n=15$ ) or HDC-treated (tumor $n=15$, spleen $n=15$ ) 4T1-bearing mice. In f, h ROS formation was normalized against the mean ROS formation of tumor-bearing control mice in each experiment. $\mathbf{i}, \mathbf{j}$ ROS formation in response to D-peptide from GR $1^{+}$(solid line, $n=3$ ) and $\mathrm{GR}^{-}$(dotted line, $n=3$ ) cells isolated from $\mathbf{i}$ tumors and $\mathbf{j}$ spleens of control EL-4-bearing mice. $\mathbf{k}, \mathbf{I}$ Proliferation of OT-1 CD $8^{+} \mathrm{T}$ cells was determined after 3 days of culture. $\mathbf{k}$ Representative histograms of CellTraceViolet-stained SIINFEKL-stimulated OT-1 $\mathrm{CD}^{+}$splenocytes in the absence of $\mathrm{GR} 1^{+}$cells $\left(\mathrm{SIINFEKL}, \mathrm{No} \mathrm{GR} 1^{+}\right.$) or in the presence of $\mathrm{GR} 1^{+}$cells isolated from spleens of control or HDC-treated EL-4-bearing mice. 1 Percentage of proliferating $\mathrm{CD} 8^{+} \mathrm{T}$ cells in the absence of stimuli $(n=3)$, in response to a control peptide $(\mathrm{gp} 100, n=3)$ or in response to an OT-1 specific peptide (SIINFEKL, $n=3$ ). In specified wells, $\mathrm{GR} 1^{+}$cells that had been isolated from control $(n=5)$ or HDC-treated $(n=6)$ EL-4-bearing mice or GR $1^{+}$cells isolated from tumor-free mice $(n=2)$ were present at a 1:1 ratio with the SIINFEKL stimulated OT-1 splenocytes during the course of proliferation. Statistical differences were evaluated using Student's $t$ test or one-way ANOVA. Linear regression was utilized to analyze correlations. ${ }^{*} p<0.05$, $* * * p<0.001$

accumulating in tumors following HDC treatment might be less immunosuppressive.

We observed that in vivo administration of HDC reduced the capacity of leukocytes isolated from EL-4 and 4T1 tumors as well as from splenocytes of EL-4-bearing mice to generate NOX2-derived ROS, with a similar trend observed for isolated GR1 ${ }^{+}$cells (Fig. 2e-h). Leukocytes recovered from tumors and spleens of EL-4-bearing control mice were separated into $\mathrm{GR} 1^{+}$and $\mathrm{GR} 1^{-}$fractions and analyzed for ROS-forming capacity. The results confirmed that ROS production was confined to the GR $1^{+}$MDSC population (Fig. 2i, j). We also observed that $\mathrm{GR} 1^{+}$cells recovered from EL-4-bearing control mice strongly suppressed $\mathrm{T}$ cell proliferation and were significantly more suppressive than MDSCs recovered from HDC-treated mice (Fig. 2k, 1).
MDSCs may also exert immunosuppression via additional mechanisms, including iNOS-derived NO production [6]. We found no significant difference in iNOS expression, as determined by flow cytometry, between MDSCs isolated form HDC-treated and control EL-4 bearing mice ( $p=0.24$, $n=4$, Students' $t$ test).

\section{HDC reduces the in vitro generation of human MDSC-like cells}

HDC was previously shown to facilitate the maturation of human and murine myeloid cells [16, 17]. We, therefore, determined effects of HDC on the cytokine-induced generation of human MDSCs in vitro. IL-6 and GM-CSF induced an MDSC-like phenotype in monocytes characterized by enhanced production of NOX2-derived ROS in response to fMLF (Fig. 3a) and reduced expression of HLA-DR in all donors $(n=12)$ albeit to a variable degree $(10-70 \%$ reduction in MFI of HLA-DR). We noted that for donors showing a robust cytokine-induced generation of MDSCs, as determined by a $>50 \%$ reduction in monocytic HLA-DR expression ( 7 out of 12 donors, Fig. 3b), incubation with HDC significantly reduced the cytokine-induced down-regulation of HLA-DR (Fig. 3c).

\section{Effect of HDC-based immunotherapy on human monocytic MDSCs}

We analyzed the content of MDSCs in blood samples from patients with AML, who had been treated with HDC in conjunction with low dose IL-2, to determine effects of treatment with HDC on human MDSCs in vivo. PBMCs from patient blood samples were analyzed for content of M-MDSCs before and after treatment cycle one and three [i.e., cycle 1 day 1 and day 21 (C1D1 and C1D21) and cycle 3 day 1 and day 21 (C3D1 and C3D21)]. The gating strategy from a representative sample is shown in Supplementary Fig. 5. M-MDSCs were found to consistently express high levels of gp91 ${ }^{\text {phox }}$, the catalytic subunit of NOX2, and $\mathrm{H}_{2} \mathrm{R}$ (Fig. 3d). The frequency and absolute counts of M-MDSCs in blood was significantly reduced during treatment with HDC/IL-2 (Fig. 3e, f). When patients were dichotomized based on above or below median reduction in total number of M-MDSCs within cycle one or between the onset of therapy (C1D1) and the end of cycle three (C3D21), it was observed that a strong reduction in M-MDSC counts significantly predicted leukemia-free survival (Fig. 3g, h).

\section{HDC enhances the anti-tumor efficacy of a-PD-1 and $\mathbf{Q}-\mathrm{PD}-\mathrm{L} 1$ antibodies}

The finding that HDC may target MDSC-related immunosuppression in humans and mice incited us to investigate if 
Fig. 3 HDC targets human MDSCs in vitro and in vivo. a-c Human monocytes were cultured in the absence of stimuli or in the presence of IL-6 and GM-CSF for 5 days to induce MDSC-like cells. a ROS production from cultured monocytes (ctrl, dotted line) and MDSClike cells (IL-6 + GM-CSF, solid line) in response to stimulation with fMLF. b Expression of HLA-DR on monocytes after 5 days of culture in absence of stimuli (Ctrl) and in presence of IL-6 and GM-CSF $(n=7)$. $\mathbf{c}$ Expression of HLA-DR on monocytes cultured for 5 days with IL-6 and GM-CSF in the absence or presence of $100 \mu \mathrm{M}$ HDC $(n=7)$. d-h AML patients in CR received HDC/IL-2 immunotherapy in 3-week cycles. $\mathbf{d}$ Expression of $\mathrm{H}_{2} \mathrm{R}$ and gp91 ${ }^{\text {phox }}$ on M-MDSCs for a representative patient. e Frequency and $\mathbf{f}$ the absolute counts of M-MDSCs before (cycle 1, day 1; C1D1) and after the first treatment cycle (cycle 1, day 21; C1D21) and at the beginning (cycle 3, day 1; C3D1) and end (cycle 3, day 21; C3D21) of the third treatment cycle. g, h Impact of M-MDSC reduction on leukemia-free survival (LFS) in patients undergoing HDC/IL-2 therapy. Patients were dichotomized by $\mathbf{g}$ the median reduction of M-MDSC counts during the first treatment cycle $(n=48)$, and $\mathbf{h}$ the median reduction of M-MDSCs from the start of cycle 1 to the end of cycle $3(n=36)$. Results were analyzed by Student's paired $t$ test or by the log rank test. $* p<0.05$, $* * p<0.01, * * * p<0.001$

HDC impacted on the efficiency of $\mathrm{CD} 8^{+} \mathrm{T}$ cell-enhancing immunotherapy. EL-4 cells expressed high levels of PD-L1 (Fig. 4a). Also, 77\% \pm 5.5 (mean \pm SEM; $n=11$ ) of intratumoral M-MDSCs and $76 \% \pm 2.3$ (mean \pm SEM; $n=11)$ of intratumoral G-MDSCs expressed PD-L1, and $77 \% \pm 2.8$ (mean $\pm \mathrm{SEM} ; n=20$ ) of tumor-infiltrating $\mathrm{CD} 8^{+} \mathrm{T}$ cells expressed PD-1 in this model. Treatment of mice with HDC in vivo did not alter the expression of PD-L1 on MDSCs or PD- 1 on $\mathrm{CD}^{+} \mathrm{T}$ cells (data not shown). Treatment of EL4-bearing mice with $\alpha$-PD-1/ $\alpha$-PD-L1 antibodies tended to reduce tumor growth rate. The combination of HDC and $\alpha-\mathrm{PD}-1 / \alpha-\mathrm{PD}-\mathrm{L} 1$ was superior to monotherapy with either HDC or $\alpha-P D-1 / \alpha-P D-L 1$ in reducing EL-4 tumor growth (Fig. 4b). Analysis of infiltrating immune populations in EL-4 lymphomas showed that $\alpha$-PD-1/ $\alpha$-PD-L1 treatment did not affect MDSC, T or NK cell accumulation but slightly increased the fraction of $\mathrm{CD} 8^{+} \mathrm{T}$ cells displaying an effector phenotype (Supplementary Fig. 6a-e). The combined regimen of HDC/ $\alpha-\mathrm{PD}-1 / \alpha-\mathrm{PD}-\mathrm{L} 1$ was also assessed in the 4T1 model. As reported elsewhere [23], 4T1 tumor growth was unaffected by $\alpha$-PD-1/ $\alpha$-PD-L1 treatment. In this model, the combination of HDC/ $\alpha-P D-1 / \alpha-P D-L 1$ was not superior to HDC alone in reducing tumor growth (data not shown).

Murine colorectal MC-38 cells expressed PD-L1 (Fig. 4a), and 70\% \pm 5.5 (mean \pm SEM; $n=11)$ of G-MDSCs and $59 \% \pm 3.2($ mean \pm SEM; $n=11)$ of M-MDSCs were also PD-L1 ${ }^{+}$. The expression of PD-1 was modest in MC-38 tumor-infiltrating $\mathrm{CD}^{+} \mathrm{T}$ cells (data not shown). MC-38 tumor growth was nevertheless strongly reduced by treatment with $\alpha$-PD-1/ $\alpha$-PD-L1; in these mice, tumors expanded during the first week after tumor cell inoculation and then regressed. Treatment with HDC further improved the antitumor efficacy of $\alpha$-PD-1/ $\alpha$-PD-L1 (Fig. 4c). At days 10 and 13 , tumor reduction in the HDC/ $\alpha-\mathrm{PD}-1 / \alpha-\mathrm{PD}-\mathrm{L} 1$ group a

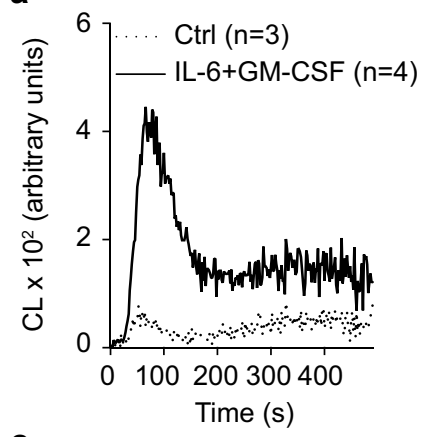

c
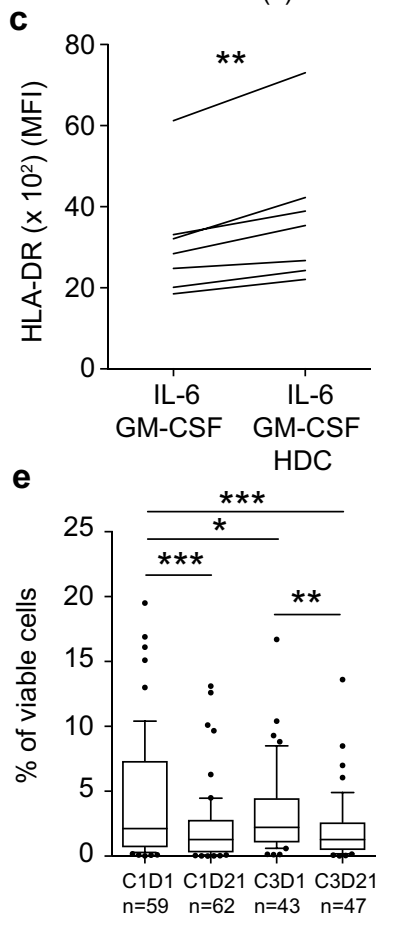

g
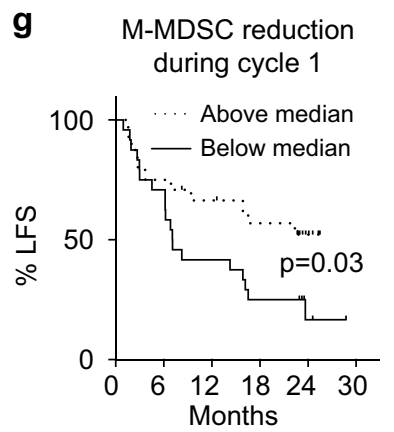

b

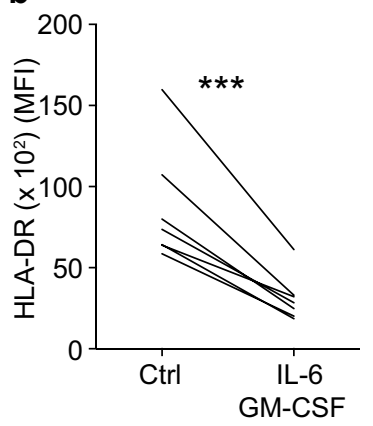

d

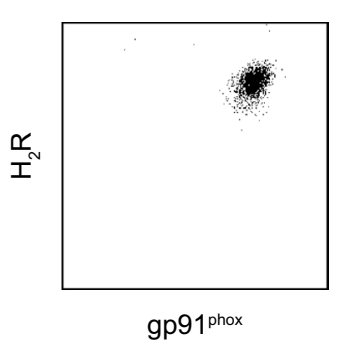

f

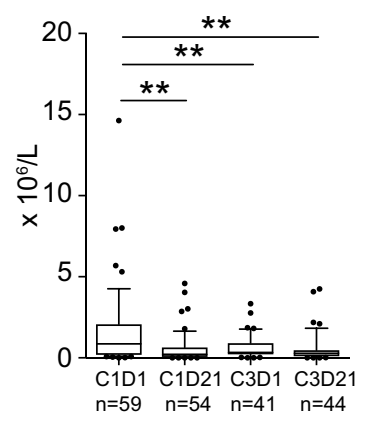

h

\section{M-MDSC reduction} until end of cycle 3

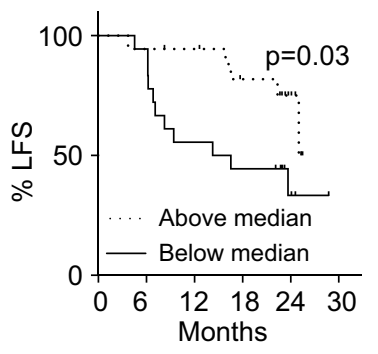

was superior to treatment with $\alpha-\mathrm{PD}-1 / \alpha-\mathrm{PD}-\mathrm{L} 1(p=0.01$ and 0.04, respectively, two-way ANOVA). At the end of the experiment $50 \%$ of mice treated with $\alpha-\mathrm{PD}-1 / \alpha-\mathrm{PD}-\mathrm{L} 1 \mathrm{mon}-$ otherapy were tumor-free whereas complete tumor clearance was noted in $100 \%$ of mice receiving HDC/ $\alpha-\mathrm{PD}-1 / \alpha-$ PD-L1. To enable analysis of MC-38 infiltrating immune populations following immunotherapy, mice were inoculated with a higher number of tumor cells to reduce the likelihood of complete tumor eradication at the experimental endpoint. 
a

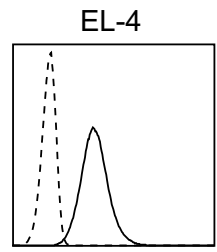

PD-L1

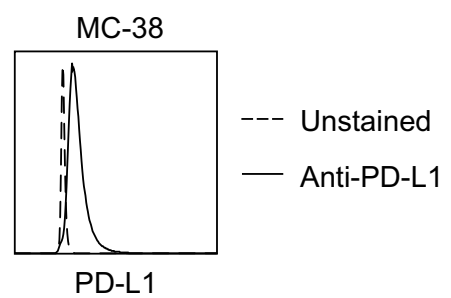

b

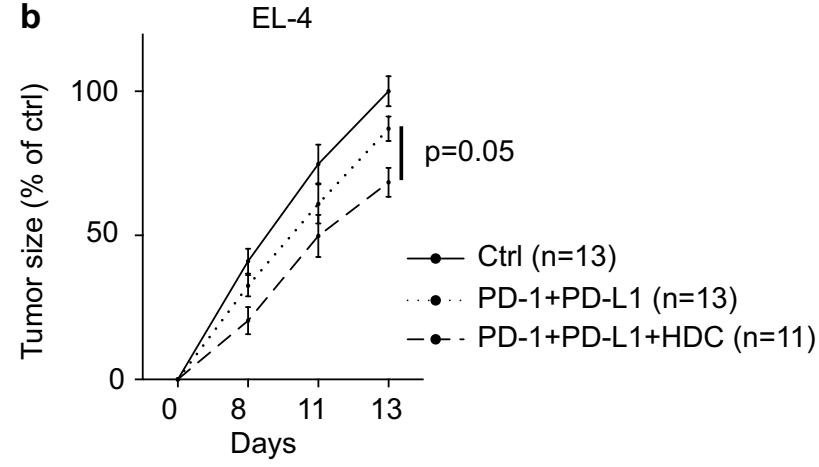

C

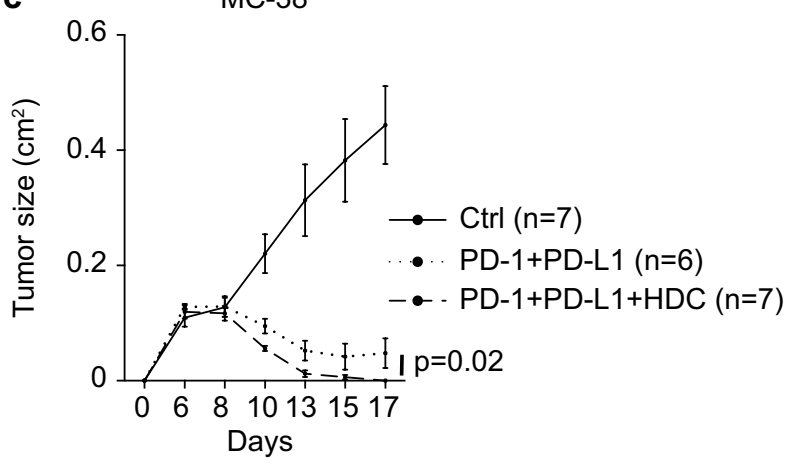

Fig. 4 HDC improves the anti-tumor efficacy of $\alpha$-PD-1/ $\alpha$-PD-L1 immunotherapy. a EL-4 and MC-38 cells were stained for expression of PD-L1 (solid line) or were left unstained (dashed line). Growth of b EL-4 and c MC-38 tumors in control (solid line), $\alpha$-PD-1/ $\alpha$-PD-L1treated (dotted line), or HDC/ $\alpha$-PD-1/ $\alpha$-PD-L1-treated (dashed line) mice. In experiments using EL-4 cells, tumor size was normalized against the mean tumor size of control mice at the end of each of four experiments, and results were analyzed using two-way ANOVA. In the MC-38 model, the difference in slope between HDC/ $\alpha$-PD-1/ $\alpha$ PD-L1 and $\alpha-\mathrm{PD}-1 / \alpha-\mathrm{PD}-\mathrm{L} 1$ treatment was analyzed by linear mixed models

The added benefit of HDC to $\alpha$-PD-1/ $\alpha$-PD-L1 therapy was demonstrated also following inoculation of a higher number of MC-38 tumor cells (Supplementary Fig. 7a). In these experiments, treatment of MC-38 tumor-bearing mice with $\alpha-\mathrm{PD}-1 / \alpha-\mathrm{PD}-\mathrm{L} 1$ or HDC/ $\alpha-\mathrm{PD}-1 / \alpha-\mathrm{PD}-\mathrm{L} 1$ tended to increase the fraction of intratumoral $\mathrm{CD} 8^{+} \mathrm{T}$ cells and significantly increased the fraction of $\mathrm{CD} 8^{+} \mathrm{T}$ cell with an effector phenotype (Supplementary Fig. 7b, c). The percentage of intratumoral $\mathrm{CD} 4^{+} \mathrm{T}$ cells was not altered, while a reduction in tumor infiltrating NK cells was noted (Supplementary Fig. 7d, e).

\section{Discussion}

This study aimed at clarifying to what extent the anti-tumor properties of HDC, an inhibitor of NOX2-derived ROS [3], may be mediated by the targeting of MDSCs. Based on results showing that HDC was devoid of anti-tumor efficacy in mice genetically deficient in NOX2 and in mice where MDSCs were depleted by GR1-neutralizing antibodies, we conclude that the anti-tumor properties of HDC rely on the presence of $\mathrm{NOX}_{2}{ }^{+} \mathrm{GR} 1^{+}$cells. Although alternative or supplementary mechanisms are conceivable, these findings confirm and extend results suggesting that HDC targets NOX2 to exert anti-tumor efficacy in murine cancer models [16, $24,25]$. We also report that treatment of mice with HDC reduced the accumulation of intratumoral MDSCs and the number of splenocytes in two experimental tumor models and that the use of a HDC-based regimen reduced MDSC counts in blood of AML patients in complete remission.

It may be asked if the reduction in the intratumoral content of MDSC and splenomegaly observed after treatment with HDC was secondary to a direct effect of HDC on tumor cells. However, HDC did not affect the in vitro proliferation of EL-4 lymphoma and 4T1 mammary carcinoma cells. Additionally, we did not observe any correlation between tumor growth on the one hand and intratumoral MDSC or splenomegaly on the other in HDC-treated mice, which argues that the reduction of MDSC was not secondary to the reduced tumor size. Instead, the reduction of MDSCs may be explained by pro-differentiating properties of HDC resulting in, i.e., increased numbers of intratumoral DCs [16]. Earlier studies also imply that endogenous histamine is critical for appropriate maturation of myeloid cells [17]. Furthermore, MDSCs isolated from Nox2-KO mice more readily differentiate into DCs and macrophages [4]. Our finding that NOX2 inhibition, via HDC, limits cytokine-induced generation of human MDSCs in vitro further supports that ROS may prevent the differentiation of myeloid cells and that HDC may overcome the insufficient differentiation. On a similar note, the administration of All-trans retinoic acid (ATRA) to tumor-bearing mice was shown to reduce MDSC counts in several experimental tumor models and to promote the maturation of MDSCs into DCs and macrophages [14]. The prodifferentiating properties of ATRA were secondary to neutralization of elevated ROS levels in MDSCs [26]. Together with the herein reported results, these findings support that NOX2-derived ROS may be targeted for appropriate myeloid cell maturation. 
In agreement with a previous study [27], the number of cells with MDSC-like phenotype was low in AML patients who had achieved CR after receiving chemotherapy. We observed that counts of M-MDSCs in blood were further reduced during the first cycle of HDC/IL-2, and that a strong reduction heralded a favorable course of disease. Since the patients had received chemotherapy approximately 2 months prior to treatment with HDC/IL-2, the distributional changes in myeloid cell populations may, in part, reflect reconstitution of hematopoietic cells. Also, despite that a previous study in renal cell carcinoma patients suggested that monotherapy with IL-2 does not affect the frequency of cells with a MDSC phenotype [28], we cannot rule out that the IL-2 component may have contributed to the observed reduction of MDSCs. With these precautions, our results suggest that treatment with HDC may affect the human MDSC compartment and that MDSCs may constitute a targetable population of relevance to the efficiency of immunotherapy in AML.

In addition to limiting the accumulation of MDSCs in tumor-bearing mice, treatment with HDC reduced the formation of NOX2-derived ROS ex vivo. In line with this finding we observed that MDSCs isolated from HDC-treated mice showed a reduced capacity to suppress $\mathrm{CD}^{+} \mathrm{T}$ cell proliferation, thus implying that HDC targets a significant effector function in MDSC-mediated immunosuppression. Notably, treatment of mice with HDC did not improve tumor infiltration of $\mathrm{CD}^{+} \mathrm{T}$ cells, despite a positive correlation between accumulation of intratumoral MDSCs and tumor-infiltrating $\mathrm{CD} 8^{+} \mathrm{T}$ cells. Instead, we observed that treatment with HDC was accompanied by the accumulation of intratumoral effector $\mathrm{CD}^{+} \mathrm{T}$ cells in EL-4-bearing mice. While further studies are required to define the detailed mechanisms involved, this finding supports that HDC may promote effector functions of tumor-infiltrating $\mathrm{CD} 8^{+} \mathrm{T}$ cells.

It was earlier reported that the targeting of MDSCs by use of colony stimulating factor 1 receptor blockade synergizes with $\alpha$-PD-1/ $\alpha$-PD-L1 checkpoint inhibition in reducing murine neuroblastoma progression in vivo [11]. These results incited us to investigate if HDC may promote the anti-tumor efficacy of checkpoint inhibition. We observed that HDC enhanced the efficacy of $\alpha$-PD-1/ $\alpha-P D-L 1$ in reducing EL-4 and MC-38 tumor growth. In the EL-4 and MC-38 models, $\alpha$-PD-1/ $\alpha$-PD-L1 treatment triggered an increased proportion of intratumoral $\mathrm{CD} 8^{+}$effector $\mathrm{T}$ cells. In the MC-38 model, $\alpha$-PD-1/ $\alpha$-PD-L1 treatment also tended to increase the presence of $\mathrm{CD}^{+} \mathrm{T}$ cells in tumors. In patients, an optimal anti-tumor efficacy of $\alpha$-PD- 1 therapy is generally believed to depend on pre-existing tumor-infiltrating $\mathrm{CD} 8^{+} \mathrm{T}$ cells [29]. The finding that treatment of mice with HDC did not trigger a significant influx of $\mathrm{CD} 8^{+} \mathrm{T}$ cells into tumors suggests that combining HDC and $\alpha$-PD- $1 / \alpha-$ PD-L1 therapy with agents that enhance $\mathrm{T}$ cell infiltration, such as chemotherapy or $\alpha$-VEGF antibodies [30, 31], might further improve anti-tumor efficacy.

In conclusion, our results suggest that in vivo treatment with HDC reduces the accumulation and immunosuppressive features of MDSCs and improves the anti-tumor efficacy of checkpoint blockade in murine EL-4 lymphoma and MC-38 colon carcinoma.

Acknowledgements We are grateful to Ingo Schmitz, Otto von Guericke University, Magdeburg, Germany for providing the EL-4 lymphoma cell line and to Göran Landberg and Sukanya Raghavan, University of Gothenburg, Sweden for providing the 4T1 mammary cancer and MC-38 colorectal cancer cell lines, respectively. We also thank Staffan Nilsson, Chalmers University, for statistical support. The authors are indebted to the participating patients and the participants in the Re:Mission Study Group.

Author contributions Author AM was the principal investigator. Authors HGW, KH and AM designed the research. Authors HGW, MSN, RK, BL, FES, AR, and AM performed experiments. Authors HGW, MSN, RK, BL, AR, and AM analyzed results. Authors HGW, $\mathrm{KH}$ and $\mathrm{AM}$ wrote the manuscript. All authors read and commented on the manuscript.

Funding This work was supported by Meda Pharma, Bad Homburg, Germany (Re:Mission Study Sponsor), the Swedish Cancer Society (Cancerfonden) (Grant no. CAN 2016/351), the Swedish Research Council (Grant no. 2016-01928), the Swedish Society for Medical Research (SSMF), the Swedish State via the ALF agreement (Grant no. ALFGBG-724881), the Erna and Victor Hasselblad Foundation, BioCARE-a National Strategic Research Program at the University of Gothenburg, and the Sahlgrenska Academy at University of Gothenburg.

\section{Compliance with ethical standards}

Conflict of interest Authors Hanna Grauers Wiktorin, Frida Ewald Sander, Anna Martner, and Kristoffer Hellstrand hold issued or pending patents protecting the use of histamine and/or $\alpha-\mathrm{PD}-1 / \alpha-\mathrm{PD}-\mathrm{L} 1$ therapy in cancer treatment. Kristoffer Hellstrand was previously a consultant to the Re:Mission study sponsor (Meda Pharma). Authors Kristoffer Hellstrand and Anna Martner have received honoraria and/ or travel grants from the study sponsor. The other authors declare no potential conflicts of interest.

Ethical approval and ethical standards The clinical phase IV trial (Re:Mission Trial, ClinicalTrials.gov; NCT01347996), was approved by the Regional ethical review board in Gothenburg on June 2, 2009, application number 267-09. All procedures of this study were performed in accordance with the 1964 Declaration of Helsinki and its later amendments or comparable ethical standards. All animal experiments were performed according to the institutional guidelines and approved by the Research Animal Ethics Committee in Gothenburg on April 4, 2014, application number 86-2014.

Informed consent Informed consent was obtained from all individual participants before enrollment to the phase IV AML Trial (Re:Mission Trial, ClinicalTrials.gov; NCT01347996).

Animal source $\mathrm{C} 57 \mathrm{BL} / 6 \mathrm{~J}$ and $\mathrm{BALB} / \mathrm{c}$ mice were purchased from the Charles River Laboratories (Sulzfeld, Germany). B6.129S6-Cybb ${ }^{\text {tmIDin }}$ (Nox2-KO) mice were originally obtained from the Jackson Laboratory (Bar Harbor, ME, USA) and bred in-house. 
Cell line authentication The EL-4 lymphoma cell line and the 4T1 mammary cancer cell line originated from the American Type Culture Collection (ATCC) and were provided by Ingo Schmitz (Otto von Guericke University, Germany) and Göran Landberg (University of Gothenburg, Sweden), respectively. The MC-38 colon carcinoma cell line originated from the Developmental Therapeutics Program Tumor Repository (Frederick National Laboratory, USA) and was provided by Sukanya Raghavan (University of Gothenburg, Sweden). All cell lines were expanded and frozen in aliquots and were cultured for no more than one week after thawing prior to use in in vivo experiments. Authentication by SNP or STR is not currently standardized for murine cell lines.

Open Access This article is distributed under the terms of the Creative Commons Attribution 4.0 International License (http://creativeco mmons.org/licenses/by/4.0/), which permits unrestricted use, distribution, and reproduction in any medium, provided you give appropriate credit to the original author(s) and the source, provide a link to the Creative Commons license, and indicate if changes were made.

\section{References}

1. Ribechini E, Greifenberg V, Sandwick S, Lutz M (2010) Subsets, expansion and activation of myeloid-derived suppressor cells. Med Microbiol Immunol 199(3):273-281. https://doi. org/10.1007/s00430-010-0151-4

2. Karlsson A, Dahlgren C (2002) Assembly and activation of the neutrophil NADPH oxidase in granule membranes. Antioxid Redox Signal 4(1):49-60. https://doi.org/10.1089/1523086027 53625852

3. Mellqvist UH, Hansson M, Brune M, Dahlgren C, Hermodsson S, Hellstrand K (2000) Natural killer cell dysfunction and apoptosis induced by chronic myelogenous leukemia cells: role of reactive oxygen species and regulation by histamine. Blood 96(5):1961-1968

4. Corzo CA, Cotter MJ, Cheng PY, Cheng FD, Kusmartsev S, Sotomayor E, Padhya T, McCaffrey TV, McCaffrey JC, Gabrilovich DI (2009) Mechanism regulating reactive oxygen species in tumor-induced myeloid-derived suppressor cells. J Immunol 182(9):5693-5701. https://doi.org/10.4049/jimmunol.0900092

5. Bronte V, Brandau S, Chen SH, Colombo MP, Frey AB, Greten TF, Mandruzzato S, Murray PJ, Ochoa A, Ostrand-Rosenberg S, Rodriguez PC, Sica A, Umansky V, Vonderheide RH, Gabrilovich DI (2016) Recommendations for myeloid-derived suppressor cell nomenclature and characterization standards. Nat Commun. https ://doi.org/10.1038/ncomms 12150

6. Marvel D, Gabrilovich DI (2015) Myeloid-derived suppressor cells in the tumor microenvironment: expect the unexpected. J Clin Investig 125(9):3356-3364. https://doi.org/10.1172/jci80005

7. Kotsakis A, Harasymczuk M, Schilling B, Georgoulias V, Argiris A, Whiteside TL (2012) Myeloid-derived suppressor cell measurements in fresh and cryopreserved blood samples. J Immunol Methods 381(1-2):14-22. https://doi.org/10.1016/j. jim.2012.04.004

8. Youn JI, Collazo M, Shalova IN, Biswas SK, Gabrilovich DI (2012) Characterization of the nature of granulocytic myeloidderived suppressor cells in tumor-bearing mice. J Leukoc Biol 91(1):167-181. https://doi.org/10.1189/jlb.0311177

9. Youn JI, Nagaraj S, Collazo M, Gabrilovich DI (2008) Subsets of myeloid-derived suppressor cells in tumor-bearing mice. J Immunol 181(8):5791-5802
10. Almand B, Clark JI, Nikitina E, van Beynen J, English NR, Knight SC, Carbone DP, Gabrilovich DI (2001) Increased production of immature myeloid cells in cancer patients: a mechanism of immunosuppression in cancer. J Immunol 166(1):678-689. https://doi. org/10.4049/jimmunol.166.1.678

11. Mao YM, Eissler N, Le Blanc K, Johnsen JI, Kogner P, Kiessling R (2016) Targeting suppressive myeloid cells potentiates checkpoint inhibitors to control spontaneous neuroblastoma. Clin Cancer Res 22(15):3849-3859. https://doi.org/10.1158/1078-0432. ccr-15-1912

12. Alizadeh D, Trad M, Hanke NT, Larmonier CB, Janikashvili N, Bonnotte B, Katsanis E, Larmonier N (2014) Doxorubicin eliminates myeloid-derived suppressor cells and enhances the efficacy of adoptive T-cell transfer in breast cancer. Cancer Res 74(1):104118. https://doi.org/10.1158/0008-5472.can-13-1545

13. Nagaraj S, Youn JI, Weber H, Iclozan C, Lu L, Cotter MJ, Meyer C, Becerra CR, Fishman M, Antonia S, Sporn MB, Liby KT, Rawal B, Lee JH, Gabrilovich DI (2010) Anti-inflammatory triterpenoid blocks immune suppressive function of MDSCs and improves immune response in cancer. Clin Cancer Res 16(6):1812-1823. https://doi.org/10.1158/1078-0432.ccr-09-3272

14. Kusmartsev S, Cheng FD, Yu B, Nefedova Y, Sotomayor E, Lush R, Gabrilovich D (2003) All-trans-retinoic acid eliminates immature myeloid cells from tumor-bearing mice and improves the effect of vaccination. Cancer Res 63(15):4441-4449

15. Maintz L, Novak N (2007) Histamine and histamine intolerance. Am J Clin Nutr 85(5):1185-1196. https://doi.org/10.1093/ ajen/85.5.1185

16. Martner A, Wiktorin HG, Lenox B, Sander FE, Aydin E, Aurelius J, Thoren FB, Stahlberg A, Hermodsson S, Hellstrand K (2015) Histamine promotes the development of monocyte-derived dendritic cells and reduces tumor growth by targeting the myeloid NADPH oxidase. J Immunol 194(10):5014-5021. https://doi. org/10.4049/jimmunol.1402991

17. Yang XD, Ai W, Asfaha S, Bhagat G, Friedman RA, Jin GC, Park H, Shykind B, Diacovo TG, Falus A, Wang TC (2011) Histamine deficiency promotes inflammation-associated carcinogenesis through reduced myeloid maturation and accumulation of CD11b(+)Ly6G(+) immature myeloid cells. Nat Med 17(1):87263. https://doi.org/10.1038/nm.2278

18. Martner A, Thoren FB, Aurelius J, Hellstrand K (2013) Immunotherapeutic strategies for relapse control in acute myeloid leukemia. Blood Rev 27(5):209-216. https://doi.org/10.1016/j. blre.2013.06.006

19. Dahlgren C, Karlsson A (1999) Respiratory burst in human neutrophils. J Immunol Methods 232(1-2):3-14. https://doi. org/10.1016/s0022-1759(99)00146-5

20. Rydström A, Hallner A, Aurelius J, Sander FE, Bernson E, Kiffin R, Thoren FB, Hellstrand K, Martner A (2017) Dynamics of myeloid cell populations during relapse-preventive immunotherapy in acute myeloid leukemia. J Leukoc Biol. https://doi.org/10.1189/ jlb.5VMA1116-455R

21. Sander FE, Nilsson M, Rydström A, Aurelius J, Riise RE, Movitz C, Bernson E, Kiffin R, Ståhlberg A, Brune M, Foà R, Hellstrand K, Thorén FB, Martner A (2017) Role of regulatory T cells in acute myeloid leukemia patients undergoing relapse-preventive immunotherapy. Cancer Immunol Immunother 66(11):14731484. https://doi.org/10.1007/s00262-017-2040-9

22. Qin H, Lerman B, Sakamaki I, Wei GW, Cha SCC, Rao SS, Qian JF, Hailemichael Y, Nurieva R, Dwyer KC, Roth J, Yi Q, Overwijk WW, Kwak LW (2014) Generation of a new therapeutic peptide that depletes myeloid-derived suppressor cells in tumor-bearing mice. Nat Med 20(6):676-681. https://doi.org/10.1038/nm.3560

23. Sagiv-Barfi I, Kohrt HEK, Czerwinski DK, Ng PP, Chang BY, Levy R (2015) Therapeutic antitumor immunity by checkpoint blockade is enhanced by ibrutinib, an inhibitor of both BTK and 
ITK. Proc Natl Acad Sci USA 112(9):E966-E972. https://doi. org/10.1073/pnas.1500712112

24. Aydin E, Johansson J, Nazir FH, Hellstrand K, Martner A (2017) Role of NOX2-derived reactive oxygen species in NK cell-mediated control of murine melanoma metastasis. Cancer Immunol Res 5(9):804-811. https://doi.org/10.1158/2326-6066.cir-16-0382

25. Kiffin R, Wiktorin HG, Nilsson MS, Aurelius J, Aydin E, Lenox B, Nilsson JA, Ståhlberg A, Thorén FB, Hellstrand K, Martner A (2018) Anti-leukemic properties of histamine in monocytic leukemia: the role of NOX2. Front Oncol. https://doi.org/10.3389/ fonc. 2018.00218

26. Nefedova Y, Fishman M, Sherman S, Wang X, Beg AA, Gabrilovich DI (2007) Mechanism of all-trans retinoic acid effect on tumor-associated myeloid-derived suppressor cells. Cancer Res 67(22):11021-11028. https://doi.org/10.1158/0008-5472. can-07-2593

27. Sun H, Li Y, Zhang ZF, Ju Y, Li L, Zhang BC, Liu B (2015) Increase in myeloid-derived suppressor cells (MDSCs) associated with minimal residual disease (MRD) detection in adult acute myeloid leukemia. Int J Hematol 102(5):579-586. https://doi. org/10.1007/s12185-015-1865-2

28. Mirza N, Fishman M, Fricke I, Dunn M, Neuger AM, Frost TJ, Lush RM, Antonia S, Gabrilovich DI (2006) All-trans-retinoic acid improves differentiation of myeloid cells and immune response in cancer patients. Cancer Res 66(18):9299-9307. https ://doi.org/10.1158/0008-5472.can-06-1690

29. Herbst RS, Soria JC, Kowanetz M, Fine GD, Hamid O, Gordon MS, Sosman JA, McDermott DF, Powderly JD, Gettinger SN, Kohrt HEK, Horn L, Lawrence DP, Rost S, Leabman M, Xiao YY, Mokatrin A, Koeppen H, Hegde PS, Mellman I, Chen DS, Hodi FS (2014) Predictive correlates of response to the anti-PD-L1 antibody MPDL3280A in cancer patients. Nature 515(7528):563563+. https://doi.org/10.1038/nature14011

30. Dirkx AEM, Egbrink M, Castermans K, van der Schaft DWJ, Thijssen V, Dings RPM, Kwee L, Mayo KH, Wagstaff J, Steege J, Griffioen AW (2006) Anti-angiogenesis therapy can overcome endothelial cell anergy and promote leukocyte-endothelium interactions and infiltration in tumors. FASEB J 20(6):621-630. https ://doi.org/10.1093/fj.05-4493com

31. Hong M, Puaux AL, Huang C, Loumagne L, Tow C, Mackay C, Kato M, Prevost-Blondel A, Avril MF, Nardin A, Abastado JP (2011) Chemotherapy induces intratumoral expression of chemokines in cutaneous melanoma, favoring T-cell infiltration and tumor control. Cancer Res 71(22):6997-7009. https://doi. org/10.1158/0008-5472.can-11-1466 